\title{
Penerapan Metode Principal Component Analysis (PCA) Untuk Identifikasi Faktor-Faktor yang Mempengaruhi Sikap Mahasiswa Memilih Melanjutkan Studi ke Kota Malang
}

\author{
Fawaidul Badri', Sulistya Umie Ruhmana Sari ${ }^{2}$,* \\ ${ }^{1}$ Fakultas Teknik, Teknik Elektro, Universitas Islam Malang, Malang, Indonesia \\ ${ }^{2}$ Fakultas Ilmu Tarbiyah dan Keguruan, Tadris Matematika, Uin Maulana Malik Ibrahim Malang, Malang, Indonesia \\ Email: ${ }^{1}$ fawaidulbadri@ unisma.ac.id, 2," ${ }^{*}$ sulistyaumieruhmanasari@uin-malang.ac.id \\ Email Penulis Korespondensi: sulistyaumieruhmanasari@uin-malang.ac.id \\ Submitted: 22/12/2021; Accepted: 29/12/2021; Published: 31/12/2021
}

\begin{abstract}
Abstrak-Masa depan suatu bangsa tergantung pada seberapa baik kualitas pendidikan dan sumber daya manusia bangsa tersebut. Perguruan tinggi sebagai salah satu bagian penting dalam dunia pendidikan yang mengemban tanggung jawab dalam upaya mencerdaskan kehidupan bangsa. Penelitian ini bertujuan untuk mengetahui faktor-faktor yang mempengaruhi sikap mahasiswa memilih melanjutkan studi ke Perguruan Tinggi Agama Islam (PTAI). Adapun yang melatarbelakangi penelitian ini adalah adanya kesenjangan yang signifikan antara peminat PTN dan PTAI serta kurangnya minat mahasiswa terhadap Perguruan Tinggi Islam menjadi sangat menarik untuk dijadikan bahan kajian penelitian untuk mengetahui hal-hal yang menjadi pertimbangan mahasiswa dalam memilih PTAI. Dari hasil penelitian menunjukkan bahwa data yang digunakan telah memenuhi uji asumsi validitas, reliabilitas, kecukupan dan kelayakan data sehingga dapat dilanjutkan pada analisis selanjutnya yaitu menggunakan analisis faktor menggunakan PCA. Semua variabel yang terdapat dalam penelitian ini memiliki nilai ekstraksi lebih dari 50\%, sehingga dapat disimpulkan semua variabel yang digunakan dapat menjelaskan faktor-faktor tersebut. Pada bagian kolom "\% of variance", karena nilai eigenvalues yang ditentukan adalah 1, maka nilai yang akan diambil memiliki eigenvalues lebih besar dari 1, ada komponen 1 , komponen 2, komponen 3, komponen 4, dan komponen 5. Jika menggunakan 5 komponen maka total faktor yang dapat menjelaskan varians adalah sebesar $20,011 \%+19,692 \%+15,935 \%+14,632 \%+10,745 \%=81,015 \%$.
\end{abstract}

Kata Kunci: PTAI; PTN; PCA; Eigenvalues; Komponen

\begin{abstract}
The future of a nation depends on how good the quality of education and human resources of the nation is. Higher education is an important part of the world of education that carries the responsibility in an effort to educate the nation's life. This study aims to determine the factors that influence student attitudes in choosing to continue their studies at Islamic Higher Education (PTAI). The background of this research is that there is a significant gap between PTN and PTAI enthusiasts and the lack of student interest in Islamic tertiary institutions is very interesting to be used as research study material to find out things that are considered by students in choosing PTAI. The results of the study indicate that the data used have met the assumption test of validity, reliability, adequacy and feasibility of the data so that it can be continued in the next analysis using factor analysis using PCA. All the variables contained in this study have an extraction value of more than 50\%, so it can be concluded that all the variables used can explain these factors. In the "\% of variance" column, because the specified eigenvalues is 1 , then the value to be taken has eigenvalues greater than 1 , there are component 1 , component 2 , component 3 , component 4 , and component 5 . If you use 5 components then the total factors that can explain the variance are $20.011 \%+19.692 \%+15.935 \%+14.632 \%+10.745 \%=81.015 \%$.
\end{abstract}

Keywords: PTAI; PTN; PCA; Eigenvalues; Component

\section{PENDAHULUAN}

Seiring perkembangan globalisasi, kata kunci yang harus dihadapi oleh seluruh bangsa Indonesia adalah persaingan yang semakin ketat. Satu-satunya cara untuk bisa memenangi sebuah persaingan adalah setiap negara harus mempunyai sumber daya manusia yang berkualitas[1][2]. Menurut World Economic Forum pada tahun 2008 tentang Global Competitiveness Index memperlihat data bahwa negara Indonesia berada pada posisi ke 54, tertinggal jauh dibawah negara-negara tetangga, seperti Singapura (peringkat 5), Malaysia (peringkat 21), dan Thailand (peringkat 34),[3][4]. Masa depan suatu bangsa tergantung pada seberapa baik kualitas pendidikan dan sumber daya manusia bangsa tersebut. Perguruan tinggi sebagai salah satu bagian penting dalam dunia pendidikan yang ikut bertanggungjawab dalam upaya mencerdaskan kehidupan bangsa mempunyai tanggung jawab dan peran yang sangat strategis untuk mengambil bagian dalam mengatasi permasalahan kualitas sumber daya manusia[5][6].

Berdasarkan informasi dari Kementrian Agama jumlah lembaga yang berhasil dikumpulkan oleh Bagian Perencanaan dan Sistem Informasi Setditjen Pendidikan Islam, untuk tahun akademik 2011-2012, secara nasional sebanyak 645 lembaga PTAI, yang terdiri dari $52(8,06 \%)$ Perguruan Tinggi Agama Islam Negeri (PTAIN) dan 593 $(91,94 \%)$ Perguruan Tinggi Agama Islam Swasta (PTAIS). Dari tahun ke tahun jumlah PTAIS terus bertambah, tahun ini meningkat mengalami kenaikan $36(6,46 \%)$ lembaga dari 557 di tahun 2011 menjadi 593, [4] [5]. Ini suatu tantangan bagi Kementrian Agama bagaimana meningkatkan citra dan kualitas Perguruan Tinggi Agama Islam di masyarakat sehingga minat untuk masuk ke PTAI meningkat[7][3]. Di sisi lain[8], pertumbuhan perguruan tinggi ini membuat para calon mahasiswa memiliki banyak alternatif dalam memilih sebuah Perguruan Tinggi Agama Islam[9]. Dari data yang ada menunjukkan jumlah calon mahasiswa dari tahun ke tahun yang mendaftar ke PTAI sebarannya sangat timpang dengan jumlah calon mahasiswa yang mendaftar ke PTN[10][9].

Oleh karena itu, berdasarkan permasalahan di atas tersebut di mana terjadinya disparitas yang cukup signifikan antara peminat PTN dan PTAI serta kurangnya minat mahasiswa terhadap Perguruan Tinggi Agama Islam menjadi 
sangat menarik untuk menjadi bahan kajian penelitian untuk mengetahui hal-hal yang menjadi pertimbangan mahasiswa dalam memilih PTAI. Salah satu metode untuk menyelesaikan masalah tersebut adalah dengan analisis multivariat (multivariat analysis) menggunakan analisis faktor. Analisis faktor adalah suatu teknik analisis yang digunakan untuk memahami sesuatu yang mendasari dimensi-dimensi atau regularitas suatu gejala. Berdasarkan halhal di atas, penulis ingin meneliti alasan alasan apa saja yang mendorong mahasiswa melanjutkan studi ke PTAI dengan mengambil sampel pada mahasiswa yang tersebar di Fakultas Ilmu Tarbiyah dan Keguruan UIN Maulana Malik Ibrahim Malang. Penelitian ini diharapkan dapat memberikan informasi atau masukan kepada fakultas untuk lebih memajukan perguruan tinggi tersebut.

\section{METODOLOGI PENELITIAN}

\subsection{Rancangan Proses Blok Diagram Penelitian}

Rancangan proses blok diagram penelitian ini bisa dilihat pada Gambar 1. Dimana data data primer, yang diambil dari responden melalui kuisioner dan angket. Dari data tersebut faktor-faktor yang mempengaruhi sikap mahasiswa PTAI sebagai perguruan tinggi pilihian akan dikelompokkan menjadi beberapa kelompok $X_{1}, X_{2}, X_{3}, X_{4}$, sampai ke $X_{n}$. dari hasil kelompok tersebut akan diproses dengan menggunakan metode ektraksi fitur Pricipal Component Analysis $(P C A)$ untuk mencari bobot-bobot analisa faktor dari data inputan[11][12]. Bobot analisa faktor ini akan menjadi kreteria penetapan untuk menentukan faktor-faktor yang paling tinggi, sehingga nilai bobot ini akan menjadi interpretasi mahasiswa yang cocok mengambil perguruan agama islam di kota malang yang sesuai dengan harapan. Analisis faktor menyederhanakan hubungan yang beragam dan kompleks dari set data atau variabel amatan engan menyatukan faktor atau dimensi yang saling berhubungan dan mempunyai korelasi pada suatu data baru yang mempunyai set faktor yang lebih.

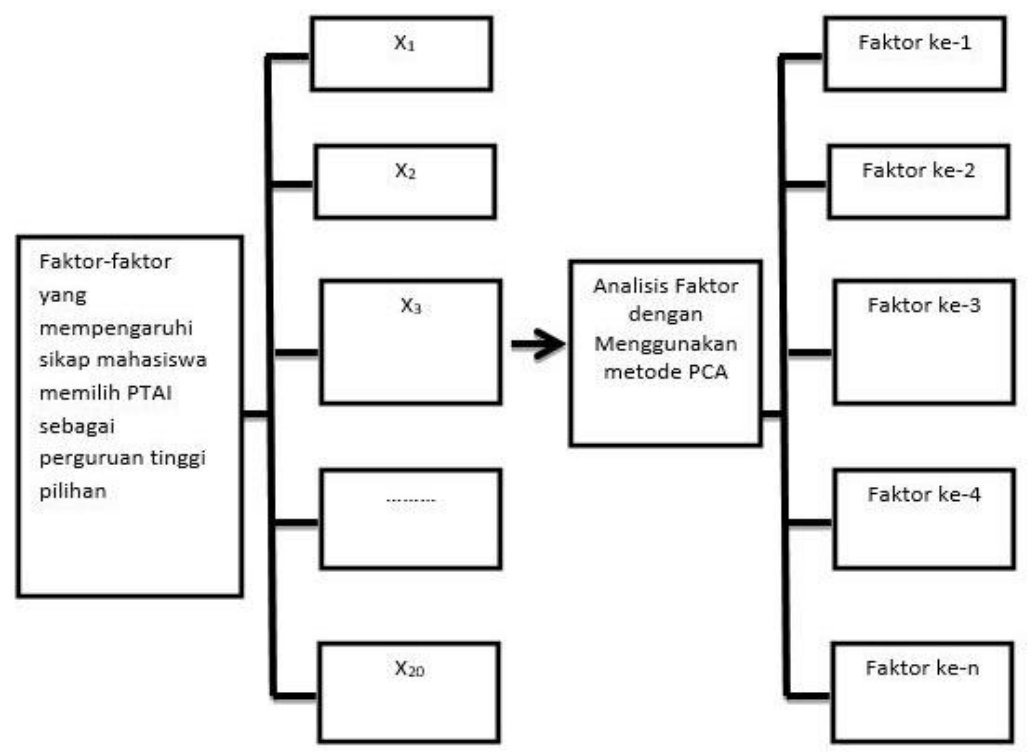

Gambar 1. Rancangan Proses Blok Diagram penelitian

\subsection{Data Penelitian}

Penelitian tentang metode Principal Component Analysis (PCA) untuk mengetahui faktor-faktor yang mempengaruhi calon mahasiswa memilih PTAI sebagai perguruan tinggi pilihan untuk melanjutkan studi di kota Malang adalah berlokasi di kota Malang dengan mengambil sampel sebanyak 250 mahasiswa PTAI yang ada di Fakultas Ilmu Tarbiyah dan Keguruan, UIN Maulana Malik Ibrahim Malang.

Secara umum data adalah segala fakta dan angka yang dijadikan bahan untuk menyusun suatu informasi. Jenis data secara umum terdapat dua, data primer dan data sekunder. Data primer adalah data yang langsung diambil dari informan, sementara data sekunder adalah data yang sudah tersedia. Sementara dalam penelitian ini menggunakan data primer, yang diambil dari responden melalui kuisioner dan angket.

\subsection{Analisa Faktor dengan mengggunakan PCA}

Penelitian tentang metode Principal Component Analysis (PCA) untuk mengetahui faktor-faktor yang mempengaruhi calon mahasiswa memilih PTAI sebagai perguruan tinggi pilihan untuk melanjutkan studi di kota Malang ini merupakan sebuah penelitian dengan pendekatan kuantitatif[7].

Analisis Komponen Utama (Principal Component Analysis) merupakan salah satu analisis multivariat yang bertujuan mengkaji struktur matriks ragam-peragam (covariance matrix) melalui linear variabel-variabel[13]. Dari segi praktis, analisis komponen utama ini bertujuan untuk mengubah dari sebagian besar variabel asli yang digunakan 
yang saling berkorelasi satu dengan yang lainnya menjadi satu set variabel baru yang lebih kecil dan saling bebas (tidak berkorelasi lagi)[1][14]. Jadi analisis komponen utama berguna untuk mereduksi data, sehingga lebih mudah untuk menginterpretasikan data tersebut.

Analisis komponen utama bertujuan untuk menyederhanakan variabel-varabel yang diamati dengan cara menyusutkan dimensinya[15][2]. Hal ini dilakukan dengan menghilangkan korelasi antar variabel yang diamati (x) dengan suatu transformasi ke varabel-variabel baru (y) yang satu sama lainnya saling bebas[16][17]. Variabel-variabel baru ini disebut dengan komponen utama. Dalam notasi matriks ditulis dengan :

$$
\mathrm{y}=\mathrm{A} x
$$

\subsection{Variabel Faktor penelitian}

Variabel yang digunakan dalam penelitian ini adalah faktor-faktor yang diduga mempengaruhi sikap seorang mahasiswa memilih PTAI sebagai perguruan tinggi pilihan yang antara lain adalah sebagai berikut :

$\mathrm{X} 1$ : Pendidikan terakhir ayah

$\mathrm{X} 2$ : Pekerjaan pokok ayah

$\mathrm{X} 3$ : Pendapatan ayah perbulan

$\mathrm{X} 4$ : PTAI yang dipilih sesuai dengan cita-cita yang ingin diraih

$\mathrm{X} 5$ : Jenis pekerjaan yang diharapkan sesuai dengan perkuliahan yang ditempuh

X6 : Pilihan PTAI berdasarkan inisiatif sendiri

X7 : Saya sering belajar di perpustakaan universitas

$\mathrm{X} 8$ : Setiap ada waktu luang selalu digunakan untuk belajar

X9: Memilih PTAI karena ingin memperdalam materi yang diterima waktu SMA

X10 : Memilih PTAI karena prestasi waktu SMA mendukung

X11 : Hubungan harmonis dalam keluarga membuat semangat belajar meningkat

$\mathrm{X} 12$ : Memilih PTAI karena banyak teman yang juga memilih PTAI

X13 : Akan belajar jika ada ujian saja

X14 : Prestasi belajar yang baik akan memperlancar memperoleh pekerjaan yang diharapkan

X15 : Banyaknya temen SMA dalam PTAI membuat lebih semangat belajar

X16 : Membaca ulang setiap materi yang disampaikan dosen

X17 : Saudara selalu memberikan motivasi untuk belajar

X18 : Lebih selektif dalam memilih PTAI karena persaingan mencari pekerjaan

X19 : Keluarga selalu memberikan dorongan dan semangat

X20 : Orang tua selalu mengingatkan ketika lalai belajar

Untuk menentukan besarnya sampel yang digunakan, maka perhitungannya berdasarkan rumus Slovin sebagai berikut :

$$
n=\frac{n}{1+N e^{2}}
$$

dimana :

$\mathrm{n}$ = ukuran sampel

$\mathrm{N}=$ ukuran populasi

e = batas error yang diinginkan (ditetapkan sebesar 5\%)

berikut:

Berdasarkan jumlah populasi penelitian, maka jumlah sampel yang mewakili populasi dapat dihitung sebagai

$n=\frac{725}{1+752\left(0,05^{2}\right)}=248=250$

Dengan demikian jumlah sampel penelitian yag digunakan adalah sebanyak 250 mahasiswa. Pengambilan sampel dalam penelitian ini adalah berdasarkan teknik Purposive Sampling. Teknik Purposive Sampling adalah pengambilan sampel yang dilakukan hanya atas dasar pertimbangan penenlitinya saja yang menganggap unsur-unsur yang dikehendaki telah ada dalam anggota sampel yang diambil.

\section{HASIL DAN PEMBAHASAN}

Pada pengujian ini dilakukan dengan menggunakan metode Principal Component Analysis dengan menggunakan beberapa variabel yang didapat dari data kuisoner, analisis data dengan menggunakan beberapa skenario, diantara uji skenario sebagai berikut:

\subsection{Skenario Model Analisis Faktor dengan Menggunakan Metode Principal Komponent Analyisis}

Dengan analisis komponen utama kita akan mereduksi data pengamatan ke dalam beberapa set data sedemikian sehingga informasi dari semua data dapat kita serap seoptimal mungkin. Dengan demikian analisis komponen utama dapat dipandang sebagai transformasi dari $\mathrm{X} 1, \mathrm{X} 1, \ldots \mathrm{Xp}$. Misal X1, X1, ... Xp mempunyai matriks varianskovarians $\sum=(\sigma 2 \mathrm{ij})$, dimana $\mathrm{i}=1,2 \ldots \mathrm{p}$ dan $\mathrm{j}=1,2, \ldots \mathrm{p}$ dan $\sum$ tersebut mempunyai nilai eigen $\lambda 1 \geq \lambda 2 \geq \ldots . \lambda$ 
$\mathrm{p} \geq 0$, maka principal component yang pertama dinyatakan dengan $\mathrm{PC} 1$ mengandung jumlah terbesar dari total variasi data. PC1 sebagai kombinasi linier dalam variabel $\mathrm{Xi}, \mathrm{i}=1,2, \ldots \mathrm{p}$ sebagai berikut :

$P C_{1}=a_{11} X_{1}+a_{12} X_{2}+a_{13} X_{3}+\ldots+a_{1 p} X_{p}$

dimana $a_{11}$ dipilih, sehingga memaksimalkan rasio dari variance $P C_{l}$ terhadap total variance, dengan pembatas bahwa $\sum a_{1 i}^{2}=1$.

Sementara, komponen utama ke- $i$ yang dibentuk berdasarkan matriks korelasi dimisalkan $W_{i}$ yang dibentuk berdasarkan variabel-variabel yang telah dibakukan $Z^{\prime}=\left(Z_{1}, Z_{2, \ldots \ldots . . .} Z_{p}\right)$ dengan $\operatorname{cov}(Z)=\rho$ didefenisikan sebagai berikut :

$W_{i}=e_{i 1} Z_{1}+e_{i 1} Z_{1}+e_{i 1} Z_{1}+\cdots+e_{i p} Z_{p}$

dimana:

$W_{i}$ adalah faktor estimasi ke- $i$;

$e_{i 1}$ adalah bobot faktor atau skor koefisien faktor;

$Z_{i}$ adalah variabel ke- $i$; dan

$p$ adalah banyaknya variabel.

\subsection{Skenario Analisis Faktor dengan Menggunakan PCA untuk Mengetahui Faktor-Faktor yang Mempengaruhi Sikap Mahasiswa Memilih Melanjutkan Studi ke Kota Malang}

Penentuan banyaknya faktor yang dilakukan dalam analisis faktor adalah mencari variabel terakhir yang disebut faktor yang tidak saling berkorelasi, bebas satu sama lainnya dan lebih sedikit jumlahnya daripada variabel awal, akan tetapi dapat menyerap sebagian besar informasi yang terkandung dalam variabel awal atau dapat memberikan sumbangan terhadap varians seluruh variabel. Penentuan berdasarkan nilai eigenvalue yaitu nilai eigenvalue lebih besar.

Pada kolom extraction dalam tabel komunalitas menunjukkan sebarapa besar sebuah variabel dapat menjelaskan faktor. Variabel pendidikan terakhir ayah (X1) memiliki nilai extraction sebesar 0,769, artinya variabel X1 dapat menjelaskan faktor sebesar 76,9\%. Variabel pekerjaan pokok ayah (X2) memiliki nilai extraction sebesar 0,646 yang artinya variabel tersebut dapat menjelaskan faktor sebesar 64,6\%. Semua variabel yang terdapat dalam penelitian ini mempunyai nilai extraction yang lebih dari 50\%, sehingga dapat disimpulkan semua variabel yang digunakan dapat menjelaskan faktor.

Berdasarkan tabel initial eigenvalues yang dihasilkan, pada kolom component terlihat bahwa terdapat 20 variabel yang ada dalam penelitian dapat mewakili faktor. Pada kolom \% of variance menggambarkan total variance yang bisa dijelaskan oleh faktor. Pada tabel dapat dilihat bahwa faktor 1 dapat menjelaskan variance sebesar 20,011\%, faktor 2 dapat menjelaskan variance sebesar 19,692\%, faktor 3 dapat menjelaskan variance sebesar 15,935 \%, faktor 4 dapat menjelaskan variance sebesar $14,632 \%$ dan faktor 5 dapat menjelaskan variance sebesar 10,745\% dan begitu seterusnya untuk faktor yang lain. Sementara, karena nilai eigenvalues yang ditetapkan adalah 1, maka nilai yang akan diambil yang mempunyai eigenvalues lebih dari 1, yaitu komponen 1, komponen 2, komponen 3, komponen 4, dan komponen 5. Jika menggunakan 5 komponen maka total faktor yang dapat menjelaskan variance adalah sebesar $20,011 \%+19,692 \%+15,935 \%+14,632 \%+10,745 \%=81,015 \%$. Dengan menggunakan program SPSS didapatkan hasil reduksi variabel tersebut menjadi 5 faktor yaitu bisa dilihat pada gambar dibawah ini.

Tabel 1. Proporsi varians untuk masing-masing komponen

\begin{tabular}{llllll}
\hline & $\boldsymbol{P C}_{\boldsymbol{1}}$ & $\boldsymbol{P C}_{\boldsymbol{2}}$ & $\boldsymbol{P C}_{\boldsymbol{3}}$ & $\boldsymbol{P C}_{\boldsymbol{4}}$ & $\boldsymbol{P C}_{\boldsymbol{5}}$ \\
\hline SS loadings & 3,18 & 3,10 & 2,62 & 2,15 & 2,38 \\
Proportion var & 0,13 & 0,12 & 0,10 & 0,09 & 0,10 \\
Cumulative var & 0,24 & 0,25 & 0,36 & 0,54 & 0,45 \\
Proportion Explained & 0,24 & 0,23 & 0,20 & 0,16 & 0,18 \\
Cumulative proportion & 0,24 & 0,47 & 0,66 & 1,00 & 0,84 \\
\hline
\end{tabular}

Seperti yang telah dibahas sebelumnya bahwa prinsip mereduksi adalah memperkecil jumlah variabel tanpa mengurangi informasi yang diberikan, maka melalui gambar di atas tersebut akan dijelaskan seberapa jauh kelima komponen (faktor) tersebut menjelaskan informasi yang terdapat dalam 20 variabel yang dianalisis. Peneliti bisa melihat pada bagian proportion variance, angka yang tertera pada kolom proportion var tersebut menunjukan kemampuan tiap faktor dalam menjelaskan variabilitas keseluruhan data.

Berdasarkan gambar di atas, proportion variance untuk PC1 (faktor 1) adalah sebesar 0,12, artinya faktor pertama mampu menjelaskan variansi dari 20 variabel sebesar $12 \%$. Kemudian faktor kedua mampu menjelaskan variansi dari keseluruhan variabel yang diamati sebesar 13\%, sedangkan variansi dari 20 variabel mampu dijelaskan oleh faktor ketiga sebesar 10\%. Faktor keempat mampu menjelaskan variabilitas keseluruhan data sebesar 9\% dan yang terakhir faktor kelima hanya mampu menjelaskan sejauh $10 \%$. Cumulative Var menunjukan gabungan dari beberapa atau keseluruhan nilai proportion var faktor dalam menjelaskan 20 variabel tersebut. Misalkan nilai 0,25 menunjukan gabungan dari proportion var faktor Agreeableness (A) dan Neuoriticism (N) yaitu 0,13 + 0,12=0,25. Artinya adalah variansi dari 25 variabel mampu dijelaskan oleh faktor 1 dan faktor 2 sebesar 0,25 atau $25 \%$. Sedangkan untuk kelima faktor yang terbentuk mampu menjelaskan variansi dari 25 variabel sebesar 54\%. 
Langkah selanjutnya dalam analisis faktor adalah menentukan anggota dari tiap-tiap faktor tersebut. Rotasi dengan metode Varimax terhadap faktor-faktor yang akan terbentuk dimaksudkan agar nilai loading factor yang dihasilkan tersebut konsisten dan tidak menimbulkan tafsiran ganda artinya setiap variabel yang akan memasuki faktor tertentu hanya pada 1 component saja yang nilainya $>0.5$. Berdasarkan hasil loading tersebut, penentuan faktor dari variabel adalah dengan melihat nilai matriks korelasi (nilai mutlak) terbesar antara tiap variabel dengan tiap faktor. Misalnya nilai terbesar untuk matriks korelasi variabel X1 adalah terdapat pada komponen PC3 (Faktor ketiga) yaitu 0,87, maka faktor X1 masuk di faktor ketiga. Begitu juga untuk variabel X20, matriks korelasi terbesar berada di komponen PC5 (faktor kelima) dengan nilai korelasi sebesar 0,88 maka varaibel X20 masuk di faktor kelima. Sehingga dari keseluruhan hasil output tersebut pada masing-masing item serta menimbang dari landasan teori terhadap penamaan setiap faktor, maka dapat dikelompokkan sebagai berikut:

1. Faktor 1 disebut faktor "Minat Mahasiswa" terdiri dari variabel X4, X6, X9, X10, dan X12. Artinya terdapat 5 variabel pada faktor "Minat Mahasiswa".

2. Faktor 2 disebut faktor "Motivasi Mahasiswa" terdiri dari variabel X7, X8, X13, X15, dan X16. Artinya terdapat 5 variabel pada faktor "Motivasi Mahasiswa".

3. Faktor 3 disebut faktor "Status Orang Tua" terdiri dari variabel X1, X2, dan X3. Artinya terdapat 3 variabel pada faktor "Status Orang Tua".

4. Faktor 4 disebut faktor "Pekerjaan yang Diharapkan" terdiri dari variabel X5, X14, dan X18. Artinya terdapat 3 variabel pada faktor "Pekerjaan yang Diharapkan".

5. Faktor 5 disebut Faktor Lingkungan terdiri dari variabel X11, X17, X19 dan X20. Artinya terdapat 4 variabel pada faktor "Lingkungan".

Pengelompokkan tersebut jika disajikan dalam bentuk tabel yaitu sebagai berikut.

Tabel 2. Faktor-faktor Memilih Studi Ke Malang

\begin{tabular}{|c|c|c|c|c|}
\hline $\begin{array}{l}\text { Faktor } 1 \\
\text { (Minat Mahasiswa }\end{array}$ & $\begin{array}{l}\text { Faktor } 2 \\
\text { (Motivasi } \\
\text { Mahasiswa) } \\
\end{array}$ & $\begin{array}{l}\text { Faktor } 3 \\
\text { (Status } \\
\text { Orang Tua) } \\
\end{array}$ & $\begin{array}{l}\text { Faktor } 4 \\
\text { (Pekerjaan yang } \\
\text { Diharapkan) } \\
\end{array}$ & $\begin{array}{l}\text { Faktor } 5 \\
\text { (Lingkungan) }\end{array}$ \\
\hline $\begin{array}{l}\text { X4 : PTAI yang } \\
\text { dipilih sesuai dengan } \\
\text { cita-cita yang ingin } \\
\text { diraih }\end{array}$ & $\begin{array}{l}\text { X7 : Saya sering } \\
\text { belajar di } \\
\text { perpustakaan } \\
\text { universitas }\end{array}$ & $\begin{array}{l}\text { X1 : } \\
\text { Pendidikan } \\
\text { terakhir ayah }\end{array}$ & $\begin{array}{l}\text { X5 : Jenis pekerjaan } \\
\text { yang diharapkan sesuai } \\
\text { dengan perkuliahan } \\
\text { yang ditempuh }\end{array}$ & $\begin{array}{l}\text { X11 : Hubungan } \\
\text { harmonis dalam } \\
\text { keluarga membuat } \\
\text { semangat belajar }\end{array}$ \\
\hline $\begin{array}{l}\text { X6 : Pilihan PTAI } \\
\text { berdasarkan inisiatif } \\
\text { sendiri }\end{array}$ & $\begin{array}{l}\text { X8 : Setiap ada } \\
\text { waktu luang selalu } \\
\text { digunakan untuk } \\
\text { belajar }\end{array}$ & $\begin{array}{l}\text { X2 : } \\
\text { Pekerjaan } \\
\text { pokok ayah }\end{array}$ & $\begin{array}{l}\text { X14 : Prestasi belajar } \\
\text { yang baik akan } \\
\text { memperlancar } \\
\text { memperoleh pekerjaan } \\
\text { yang diharapkan }\end{array}$ & $\begin{array}{l}\text { X17 : Saudara selalu } \\
\text { memberikan } \\
\text { motivasi untuk } \\
\text { belajar }\end{array}$ \\
\hline $\begin{array}{l}\text { X9 : Memilih PTAI } \\
\text { karena ingin } \\
\text { emmperdalam materi } \\
\text { yang diterima waktu } \\
\text { SMA }\end{array}$ & $\begin{array}{l}\text { X13 : Akan belajar } \\
\text { jika ada ujian saja }\end{array}$ & $\begin{array}{l}\text { X3 : } \\
\text { Pendapatan } \\
\text { ayah } \\
\text { perbulan }\end{array}$ & $\begin{array}{l}\text { X18 : Lebih selektif } \\
\text { dalam memilih PTAI } \\
\text { karena persaingan } \\
\text { mencari pekerjaan }\end{array}$ & $\begin{array}{l}\text { X19: Keluarga } \\
\text { selalu memberikan } \\
\text { dorongan dan } \\
\text { semangat }\end{array}$ \\
\hline $\begin{array}{l}\text { X10 : Memilih PTAI } \\
\text { karena prestasi waktu } \\
\text { SMA mendukung }\end{array}$ & $\begin{array}{l}\text { X15 : Banyaknya } \\
\text { temen SMU dalam } \\
\text { PTAI membuat } \\
\text { lebih semangat } \\
\text { belajar }\end{array}$ & & & $\begin{array}{l}\text { X20 : Orang tua } \\
\text { selalu mengingatkan } \\
\text { ketika lalai belajar }\end{array}$ \\
\hline $\begin{array}{l}\text { X12 : Memilih PTAI } \\
\text { karena banyak teman } \\
\text { yang juga memilih } \\
\text { PTAI }\end{array}$ & $\begin{array}{l}\text { X16 : Membaca } \\
\text { ulang setiap materi } \\
\text { yang disampaikan } \\
\text { dosen }\end{array}$ & & & \\
\hline
\end{tabular}

\section{KESIMPULAN}

Berdasarkan fokus penelitian, paparan data dan temuan penelitian serta analisis data maka hasil penelitian ini dapat disimpulkan bahwa setelah melakukan aplikasi metode analisis faktor dengan menggunakan metode PCA untuk mengetahui faktor-faktor yang mempengaruhi sikap mahasiswa memilih melanjutkan studi ke PTAI, maka dapat disimpulkan komponen yang terbentuk sebanyak 5 komponen.

\section{REFERENCES}

[1] J. I, "Dampak Penerapan Principal Component Analysis ( Pca ) Dalam Clustering Curah Hujan Di Pulau Jawa ,Bali , Dan Lombok [ Impact of Principal Component Analysis ( Pca ) Implementation on Rainfall Clustering Over Java, Bali and 
Lombok Islands ].," J. Sains Dirgant., no. 11, pp. 97-108, 2014

[2] N. M. Z, "PENERAPAN PRINCIPAL COMPONENT ANALYSIS (PCA) DALAMPENENTUAN FAKTOR DOMINAN YANG MEMPENGARUHI PRESTASI BELAJAR SISWA (Studi Kasus : SMK Raksana 2 Medan).," J. Teknol. Inf., vol. 1, no. 3, p. 41, 2019.

[3] M. Wangge, "Penerapan Metode Principal Component Analysis (PCA) Terhadap Faktor-faktor yang Mempengaruhi Lamanya Penyelesaian Skripsi Mahasiswa Program Studi Pendidikan Matematika FKIP UNDANA,” J. Cendekia J. Pendidik. Mat., vol. 5, no. 2, pp. 974-988, 2021.

[4] B. T.A, Confirmatory factor analysis for applied research. NewYork.: The Guilford Press, 2006.

[5] E. James F, B. Rogre D, and M. Paul W, Perilaku Konsumen. Jakarta: Binaputra Aksara, 1994.

[6] R. A and P. D. E, "Analisis Faktor Penghambat Skripsi Mahasiswa Jurusan Pendidikan Guru Sekolah Dasar Universitas Wijaya Kusuma Surabaya. Jurnal Pendidikan Dasar.," J. Pendidik. Dasar, vol. 1, no. 10, pp. 101-114, 2019.

[7] M. Z. Nasution, "PENERAPAN PRINCIPAL COMPONENT ANALYSIS (PCA) DALAM PENENTUAN FAKTOR DOMINAN YANG MEMPENGARUHI PRESTASI BELAJAR SISWA (Studi Kasus : SMK Raksana 2 Medan),”J. Teknol. Inf., vol. 3, no. 1, p. 41, 2019.

[8] G. V, Teknik Analisis dalam Penelitian Percobaan. Bandung: Tarsito, 1992.

[9] M. C. Utami, "Analisis Faktor-Faktor Yang Mempengaruhi Dosen Dalam Melanjutkan S3 Dengan Metode Principal Component Analysis (Studi Kasus: Program Studi Si/Ti Fst Uin),” J. Sist. Inf., vol. 6, no. 1, pp. 1-7, 2013.

[10] F. Elfira, "Penerapan Analisis Faktor dalam Menentukan Faktor-faktor yang Mempengaruhi Mahasiswa dalam Memilih Jurusan Matematika Fakultas Sains dan Teknologi Universitas Islam Negeri Alauddin Makassar,” Msa, vol. 3, no. 1, pp. 2936, 2014

[11] P. D and S. A. R, "Perbandingan Metode Principal Component Analysis (PCA) dengan Metode Hidden MarkovModel (HMM) dalam Pengenalan Identitas," J. Inform., vol. 2, no. 3, pp. 68-81, 2015.

[12] P. B. E. and S. T, "Analisis Principal Component Analysis (PCA) Untuk Mereduksi Faktor-Faktor yang Mempengaruhi Kualitas Kulit Kikil Sapi.," in Prosiding Seminar \& Konferensi Nasional IDEC, 2019, p. C01.1-C01.10.

[13] M. Jamaris, "SATIN - Sains dan Teknologi Informasi Analysis untuk Menentukan Minat Calon Mahasiswa Masuk," Satin, vol. 5 , no. 2, 2019.

[14] S. W. A, A. F, H. A, and H. S, "Identifikasi Faktor-Faktor Yang Mempengaruhi Penyelesaian Skripsi Pada Mahasiswa S1 Psikologi Di Kota Semarang,” J. Penelit. Pendidik., vol. 2, no. 34, pp. 155-160, 2017.

[15] M. D. F, Multivariate Statistical Methods. New York: McGraw-Hill International Book Company, 1976.

[16] W. DW and J. R.A, Applied Multivariate Statistical Analysis. New Jersey: Englewood Chiffs Prentice Hall, 1992.

[17] L. L, Kupper, D. G, and Kleinbaum, Applied Regression Analysis and Other Multivariable Methods. Massachuset: Duxbury Press, 1978. 